\title{
Yeltsin loses scientists' support in swing to opponent Yavlinsky
}

Moscow. A substantial number of Russian scientists, disenchanted by the failure of President Boris Yeltsin to deliver on his promises of support, have decided to put their weight behind one of his leading challengers, the reformist economist Grigory Yavlinsky, in next Sunday's elections.

Until recently, the scientific community had been among Yeltsin's strongest supporters, providing him with significant backing in his power struggles with the former president Mikhail Gorbachev. Many, for example, were active in setting up the Electors Club of the Academy of Sciences (ECAS), a body originally set up to run the successful campaign of physicist Andrei Sakharov as a people's deputy.

This time round, however, the organization is split down the middle in its allegiance. While half of its members continue to support Russian Choice, the pro-Yeltsin bloc headed by vice-premier Egor Gaidar, an equal number have been campaigning actively on Yavlinksy's behalf.

Those who have deserted the Yeltsin camp claim that their decision is based less on disagreements over the specific policies being offered for science (those promoted by Gaidar and Yavlinksy are remarkably similar) than on their confidence in the individuals involved.

Alexei Zakharov, a candidate for the State Duma (the lower chamber of the future two-chamber parliament) points out that there is a wide range of political views in the scientific community. But he says that active support from members of ECAS played a key role in obtaining the 10,000 signatures needed for Yavlinsky's nomination.

The disillusionment of the scientific community with the Yeltsin administration has been growing rapidly in recent months, explained partly by what is seen as the deterioration of the social standing of scientists. Two events in particular have shaken the scientific community's loyalties.

One was last spring. On the eve of the referendum, Yeltsin solicited the support of the scientific intelligentsia and at the same time issued a directive that would have almost doubled their salaries. But after he won the referendum, Yeltsin issued a decree virtually cancelling the directive.

The second event was the October uprising. Most (but not all) scientists supported Yeltsin's dismissal of the Russian Parlia- ment. But many believed the shoot-out at the Russian White House was completely unnecessary.

In next Sunday's elections, four separate blocs - including those headed by Gaidar and Yavlinsky - have promised to introduce policies to boost Russian science.

Not all scientists are disenchanted with Yeltsin. Vladimir Kadyshevsky, chairman of the recently created Union of Russian Scientific Communities (URSC), and director of the Joint Institute of Nuclear Research in Dubna near Moscow, argues that Gaidar's Russia's Choice should receive support from scientists.

Kadyshevsky says that he reached this conclusion after meeting Gaidar, whom he describes as "a serious politician who understands the need to save science in Russia, and that neglecting science today means facing severe consequences in the future."

Kadyshevsky is hoping that his meeting with Gaidar will help ease some of the problems facing the scientific community.

\section{NIH acts to reduce discrimination}

Washington. The US National Institutes of Health (NIH) will shortly fill four senior positions with women or non-whites as part of its drive to counter alleged discrimination in its recruitment practices, according to Ruth Kirschstein, the deputy director.

This move follows recurrent accusations of racial and sexual discrimination against the NIH over employment practices at its campus in Bethesda, Maryland.

Kirschstein revealed the four pending appointments - each at the 'senior executive' level, and as such subject to confirmation by Donna Shalala, the secretary of health - in an interview following a meeting last week at which NIH's senior academic advisers had been told that the biomedical research body must rely on action, not words, to counter the allegations.

"If you made one appointment at a senior level for every task force you've set up, your problem would be solved," Clifford Alexander, a lawyer who has advised NIH on improving its equal opportunities strategy, told the director's advisory council.

Kirschstein acknowledged that discrimination had given the NIH unfavourable publicity, and that much of it was deserved. She
For example, many research institutes are facing electricity bills which exceed their total annual budget.

But Yavlinksy's supporters, who admit that their candidate's bloc is unlikely to win but hope that he may become the main opposition voice in the new parliament, claim that he is more committed to introducing the reforms that Russian science needs.

Zakharov, for example, said in a recent radio interview that scientists, now the most badly paid sector of the economy, were suffering directly from the destruction of the Soviet state as the state had been the only serious supporter of their work.

But there was no way back. Zakharov said that the Yavlinsky bloc was proposing that the current government policy of selective support for scientists - which means in practice that the allocation of most research money is decided by government officials - should be replaced by a more competitive distribution of funds.

Feasibility studies should be carried out to look into the increased privatization of scientific activity, said Zakharov. And he also said that research scientists who did not meet international standards should be retrained with government help to equip them for other tasks.

Vladimir Pokrovsky

pledged to change the institute's culture. "NIH is here to do research, and some people take the view that they don't want to do anything that will slow down the research," said Kirschstein. "That has to change."

Two facts have been highlighted as evidence of discrimination at the NIH. One is that although two-fifths of biomedical researchers qualifying from US colleges are women, they hold few senior posts at the institutes. The second is that about half the staff who carry out menial jobs at the Bethesda campus are black, but only a small proportion of even junior researchers are.

If any of the predominantly white and male advisory council felt that the issue was being exaggerated, they kept it to themselves during a lengthy discussion which dominated the council's first session under new director, Harold Varmus.

Current plans to reduce discrimination at $\mathrm{NIH}$ include expanding its equal employment opportunity office, enabling the office to take monthly progress reports from each of the 26 institutes. Sanctions will in future be imposed on managers found to have victimized those who complain about discrimination.

Colin Macilwain 